\title{
Research Paper: Male Infertility and Its Impact on Women's Sexual Behaviors: Need Attention to Psychological Problem as a Psychological Rehabilitation
}

\author{
Fatemeh Ghavi $^{1}$, Leili Mosalanejad ${ }^{2 *}$, Saeed Abdollahifard ${ }^{3}$, Masomeh Golestan Jahromi
}

1. Department of Midwifery, School of Nursing and Midwifery, Shiraz University of Medical Sciences, Shiraz, Iran.

2. Research Center for Social Determinants of Health, Jahrom University of Medical Sciences, Jahrom, Iran.

3. Student Research Committee, School of Medicine, Shiraz University of Medical Sciences, Shiraz, Iran.

Article info:

Received: 23 Dec. 2016

Accepted: 05 Apr. 2017

Keywords:

Burnout, Assertiveness, Infertility, Sexual dysfunction, Sexual disorder, Psychological rehabilitation
Citation: Ghavi F, Mosalanejad L, Abdollahifard S, Golestan Jahromi M. Male Infertility and Its Impact on Women's Sexual Behaviors: Need Attention to Psychological Problem as a Psychological Rehabilitation. Iranian Rehabilitation Journal. 2017; 15(2):87-94. https://doi.org/10.18869/NRIP.IRJ.15.2.87

https://doi.org/10.18869/NRIP.IRJ.15.2.87 


\section{Introduction}

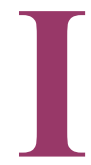

nfertility is defined as the inability to conceive despite unprotected sex (without using contraceptive methods) for a year [1] The population of sterile people has recently increased, with approximately $30 \%$ of individuals at a fertile age having infertility. About $35 \%$ of both genders fail to impregnate; $20 \%$ of couples cannot conceive because of factors contributing to males and females combined, and $10 \%$ are unable to conceive due to unknown factors [2].

The prevalence of primary infertility in Iran has been reported to be $20.2 \%$, which is significantly higher than the global mean (8\%-12\%) [3]. Male factor is responsible for $51.2 \%$ of infertility in the world and $19 \%-57 \%$ of infertility in Europe [1]. Infertility is considered a stressful experience and a threatening crisis for individual, marital, family, and social stability in all cultures worldwide [4]. Nothing threatens the couples' relationship as infertility in Africa and Asia [5]. Sexual dysfunctions including couple burnout, sexual dysfunction beliefs, and reduced sexual assertiveness are a problem for many couples, especially infertile couples.

Burnout is a state of fatigue that arises due to a mismatch between expectations and reality. Burnout is associated with physical burnout (feelings of fatigue, malaise, lethargy, etc.), emotional burnout (feelings of hopelessness, inability to solve problems, frustration, sadness, feelings of emptiness, meaninglessness, depression, etc.) and psychological burnout in the form of reduced self-belief, negative opinion toward the spouse, a sense of despair and frustration to the spouse, self-frustration, and self-dislike [6]. Couple burnout is a gradual process, and the accumulation of frustration and tensions of everyday life will cause mental erosion and eventually lead to burnout [7]. Many factors play a role in sexual burnout such as irrational thoughts, unrealistic expectations, and ups and downs of life, and its extent depends on the compatibility of couples and their beliefs [8]. Many evidences show a positive relationship between marital burnout, helplessness, marital relationship, sexual satisfaction, and infertility [9-13].

Sexual beliefs are characterized by perception of sexual interactions. Based on the cognitive theory, people create views concerning their sexual interactions [14] and develop beliefs about their sexual abilities and identity. The relationship of sexual behaviors and dysfunction with sexual beliefs has been studied. Many research works have showed the relationship between infertility and the sense of ineffectiveness, sexual inactivity and marital incompatibility, and negative self-beliefs or sexual dysfunction beliefs [15-19].

Others believe that assertiveness is standing up for your rights while respecting those of others; it is also a direct, honest, and appropriate way of expressing one's own thoughts, feelings, and beliefs [20]. In fact, assertiveness means that our and others' thoughts, opinions, beliefs and feelings are equally important as long as it does not harm the rights of others [21]. Assertiveness greatly raises a person's self-confidence. A lack of assertiveness means people do not know their feelings, thoughts, needs and beliefs well, do not share them with others, and are also unable to act strongly to meet their demands.

Sexual assertiveness is a subtype of sexual relationship and is considered as individual's ability to establish a sexual relationship to meet sexual needs with the sexual partner or spouse. Sexual assertiveness is an important factor in sexual satisfaction in women's sexual relationships with their husbands. Studies have reported a strong relationship between sexual self-esteem, sexual assertiveness, and sexual satisfaction. Studies have also showed that sexual assertiveness and self-esteem are two important factors that can affect sexual satisfaction levels [22]. Murphy found that low self-esteem and overall low sexual assertiveness are the personality traits of women who have experienced sexual coercion in their marital relationships [23].

Healthy sexual function and appropriate marital relationships are pillars of a sustainable and intimate relationship and are also important factors of a couple's physical and mental health, and the continuity of a family depends on these relationships. Unfortunately, in most parts of the world, women are not allowed to have appropriate sexual behavior, and female sexual dysfunction affects many aspects of their lives directly or indirectly [24]. So, making family members and their relationships healthy will certainly have positive effects on society.

Although much research has been done on sexual dysfunction in infertile women, few studies have been conducted on burnout, sexual beliefs and sexual assertiveness in women with infertile husbands. Therefore, given the importance of healthy sexual relationships between couples and its effects on marital satisfaction and, ultimately, on public health, we decided to conduct this research to examine male infertility and its influence on women's sexual behaviors. It is also important to note that since women sexuality is highly contextual, little research has been done on women's sexual problems. 
Moreover, fewer women talk about it, and only a fraction of them treat their problems.

\section{Methods}

This cross-sectional descriptive study included female individuals attending a fertility center in Yazd, Iran between 1 September 2013 and 10 March 2014 who were selected via convenience sampling. Two-hundred women who met the inclusion criteria were then divided into two groups (with infertile and fertile husbands) of 100 each. The inclusion criteria were being in the age range of 15 to 40 years, no disability from physical illness or chronic diseases in women and their husbands, no mental disorders, and non-consumption of psychotropic drugs, antidepressants, cardiovascular, and anti-hypertensive drugs. Data from the two groups were matched by age, socio-economic status, level of education, and so on. These selected women were referred to clinics and other outpatient centers related to Jahrom University of Medical Sciences. These centers will cover different people from Fars Province and the diversity of these people was responsive for our work. All questionnaires were filled out by researchers by asking each woman individually.

\section{Research tools}

Participants completed the written consent forms to participate in this study. All the participants were assured of confidentiality and anonymity. Then three questionnaires of the Hurlbert Index of Sexual Assertiveness (HISA), Sexual Dysfunctional Beliefs Questionnaire (SDBQ), and Couple Burnout Measure (CBM) were completed by the two groups, and the results were compared between the groups.

\section{The Hurlbert index of sexual assertiveness}

The HISA test was developed in 1992 by David Farley Hulbert for assessing female sexual assertiveness in interaction with others and consisted of 25 items with 5-point Likert scale. The Cornbrash's alpha coefficient was 0.79 for the scale in Iran [25].

\section{Sexual Dysfunctional Beliefs Questionnaire (SDBQ)}

SDBQ is a 40-item questionnaire for assessing sexual beliefs and stereotypes that are considered as predisposing factors for the development of female and male sexual dysfunction. The questionnaire was presented in two versions for men and women measuring the beliefs of each gender separately. The subjects were asked to determine their agreements on a 5 point scale from
$1=$ strongly disagree to $5=$ strongly agree. Test-retest reliability for men's and women's version with a fourweek interval had a significant and satisfactory correlation $(r=0.80$ and $r=0.73$ ). Cronbach's alpha was 0.93 for men's version and 0.81 for women's version; this confirmed the internal consistency of the questionnaire. In the Persian version of this questionnaire, the internal consistency was obtained as 0.89 for men's version and 0.80 for women's version. Also, its convergent validity with dysfunctional attitude scale was $0.76[15,26]$.

\section{Couple Burnout Measure (CBM)}

This questionnaire is a self-assessment tool designed to measure marital burnout between couples [6]. It consists of 21 items representing the burnout syndrome and has three main components of physical exhaustion (such as fatigue, lethargy, and sleep disorder), emotional exhaustion (depression, disappointment, entrapment), and mental exhaustion (such as worthlessness, frustration and anger toward spouse). It is also related to the couple's relationship (e.g., "disappointed with partner," rather than "disappointed with "people."). All of these items are answered on a 7-point scale $(1=$ never, $7=$ always). CBM validity assessment revealed an internal consistency of variables from 0.84 to 0.90 .

In Iran, Navidi reported Cronbach's alpha of this questionnaire on 240 subjects (120 nurses and 120 teachers) as 0.86 [27]. In the study of Adibrad and Adibrad, the test retest reliability coefficient was $0.89,0.76$, and 0.66 for 1-, 2-, and 4-month intervals, respectively. Internal consistency was measured for most subjects by alpha coefficient, which was between 0.91 and 0.93 [28]. All the questionnaires have been previously used for diabetic patients and have been normalized for Iranian people [29].

\section{Ethical consideration}

All the participants were satisfied with the project, and participate in the research willingly. The proposal extracted from this paper was confirmed by the Ethics Committee of Jahrom University of Medical Sciences.

\section{Analysis}

Data analysis was done using descriptive and analytical statistics as frequency, percentage, mean, variance, and standard deviation. Pearson's correlation, step-vise regression and multiple analyses (MNOVA) were used for analyzing the data. The confidence level was identified at $\mathrm{P}<0.05$. 


\section{Results}

Most participants have in age range 15-25, marriage age 1-5 years ,higher education as a educational level and most of them were unemployed (Table 1). There were no significant differences between demographic variables in the two groups (Table 1).The results of the infertile group showed that $37.6 \%$ of infertility causes are related to unknown factors, $28.4 \%$ to male factors, and the remaining are related to female factors.

As a result, the mean for couple burnout in the two subscales of emotional burnout $(\mathrm{P}=0.01)$ and psychological burnout $(\mathrm{P}=0.001)$ was statically significant. There were also differences between the mean scores of the two groups in SDBQ subcategories in sexual self-thought $(\mathrm{P}=0.002)$ and sexual dysfunctional beliefs $(\mathrm{P}=0.04)$. Sexual assertiveness in women with fertile husbands was higher than in the other group, but there is no significant difference in sexual assertiveness in two groups (Table 2 ). Other results from variance analysis showed that the difference between couple burnout, and sexual dysfunctional beliefs (Table 3 ) $\mathrm{P}=0.01 \& \mathrm{P}=0.003$ respectively.

In other words, the difference between the two groups by least significance difference (LSD) test confirmed the difference between couple burnout and sexual dysfunction scores between two groups. Women with infertile husbands had higher levels of couple burnout and sexual dysfunction beliefs (Table 4) level of significance were $\mathrm{P}=0.001$ and $\mathrm{P}=0.03$ respectively.

\section{Discussion}

The present study aimed to examine couple burnout, false sexual beliefs and sexual assertiveness in women with infertile husbands compared to women with fertile husbands. Our results suggest that infertility serves as a chronic stress and a continuing problem on sexual dysfunction in women. The results showed that $37.6 \%$ of the causes of infertility are related to unknown factors, $28.4 \%$ to male factors and the remaining are related to female factors.

It was also found that the mean for couples' burnout in the two subscales of emotional burnout and psychological burnout were statically significant in both the groups. McCabe et al. showed that sexuality is an important aspect of people's lives and includes a wide range of cognition, emotion and behavior [29]. McCarthy et al. believed that sexuality is an integral part of human life with a multidimensional content [30]. Women's sexual response is a combination of interpersonal, contextual, personal psychological and biological factors that led to women's sexual response [31]. Also women's sexual arousal is strongly modulated by emotions and cognitions [32].

Contextual factors including number of community characteristics, social policy and roles, socioeconomic

Table 1. Descriptive variables from personal characteristics

\begin{tabular}{|c|c|c|c|}
\hline \multicolumn{3}{|c|}{$\begin{array}{l}\text { Women With Infertile Husbands } \\
\qquad \mathrm{N}=100\end{array}$} & \multirow{2}{*}{$\begin{array}{l}\text { Women With Fertile Husbands } \\
\qquad \begin{array}{c}\mathrm{N}=100 \\
\text { No. (\%) }\end{array}\end{array}$} \\
\hline Variables & Range & No. (\%) & \\
\hline \multirow{3}{*}{ Age } & $15-25$ & $50(64.1 \%)$ & $48(64 \%)$ \\
\hline & $25-35$ & $26(33.3 \%)$ & $27(36 \%)$ \\
\hline & $36-45$ & $2(2.6 \%)$ & - \\
\hline \multirow{4}{*}{ Marriage duration } & $1-5$ & $41(52.6 \%)$ & $39(51.3 \%)$ \\
\hline & $6-10$ & $28(35.9 \%)$ & $28(36.6 \%)$ \\
\hline & $11-15$ & $8(10.3 \%)$ & $3(10.5 \%)$ \\
\hline & $16-20$ & $4(1.3 \%)$ & $1(1.3 \%)$ \\
\hline \multirow{3}{*}{ Education level } & Primary & $8(10.8 \%)$ & $8(10.5 \%)$ \\
\hline & High school diploma & $28(35.5 \%)$ & $26(34.2 \%)$ \\
\hline & Higher education & $43(54.4 \%)$ & $42(55.3 \%)$ \\
\hline \multirow{3}{*}{ Occupation } & Employed & $16(21.9 \%)$ & $17(24 \%)$ \\
\hline & Self-employed & $5(6.8 \%)$ & $4(5.6 \%)$ \\
\hline & Unemployed & $52(71.2)$ & $50(70.4 \%)$ \\
\hline
\end{tabular}

P>0.05 for all differences between groups; Age: 0.36; Marriage duration: 0.52; Education levels: 0.60

Iranian Rehabilitation Journal 
Table 2. The descriptive analysis of research variables in participant

\begin{tabular}{|c|c|c|c|c|c|c|}
\hline \multirow{2}{*}{ Tests } & \multirow{2}{*}{ Variable } & \multicolumn{2}{|c|}{$\begin{array}{l}\text { Women With Infertile Husband } \\
\qquad \mathrm{N}=100\end{array}$} & \multicolumn{2}{|c|}{$\begin{array}{l}\text { Women With Fertile Husband } \\
\qquad \mathrm{N}=100\end{array}$} & \multirow{2}{*}{$\mathbf{P}^{*}$} \\
\hline & & Mean & SD & Mean & SD & \\
\hline \multirow{3}{*}{ CBM } & Physical burnout & 23.95 & 4.65 & 23.42 & 4.62 & 0.43 \\
\hline & Emotional burnout & 20.84 & 8.31 & 16.93 & 6.84 & $0.01^{*}$ \\
\hline & Psychological burnout & 28.34 & 9.03 & 24.18 & 6.94 & $0.001^{*}$ \\
\hline HISA & Sexual assertiveness & 70.92 & 11.56 & 71.84 & 11.27 & 0.47 \\
\hline \multirow{5}{*}{ SDBQ } & Age related beliefs & 29.36 & 4.54 & 27.94 & 5.88 & 0.08 \\
\hline & Sexual self-thought & 21.553 & 4.64 & 19.54 & 4.30 & $0.002^{*}$ \\
\hline & Denying emotion's priority & 29.82 & 4.51 & 28.65 & 4.05 & 0.05 \\
\hline & Motherhood priority & 24.55 & 6.97 & 23.60 & 7.43 & 0.36 \\
\hline & Sexual dysfunctional beliefs & 21.80 & 4.28 & 20.50 & 4.51 & $0.04^{*}$ \\
\hline
\end{tabular}

*P significant $(\mathrm{P}<0.05)$ from student t-test.

Iranian Rehabilitation Journa

status, religion and value, female labor force participation, population differences, and family planning service availability affect sexual behavior and expectations [33]. Infertility is another important factor that has been addressed in many studies. Infertility causes considerable suffering including the loss of security or health of marital relationships and sexual dissatisfaction in couples [34-38].

Partner mood and mental health, nature and duration of current relationship, social values and beliefs regarding the sexual problems also affect sexual behavior. The results of this study showed that mental and emotional burnout on one hand and sexual dysfunctional beliefs on the other hand are higher than average in women with infertile husbands. Several studies have confirmed this issue. In a review study by Peng Tao et al., infertility was found to cause changes in sexual self-belief, sexual relationship, and sexual function $[39,40]$.

The present study showed that the mean score of sexual assertiveness is less in women with infertile husbands than in women with fertile husbands. It should be noted that limited research works have focused on the effect of husband's infertility on women sexual assertiveness. One study on the sexual life of infertile men showed that infertile couples who were recently diagnosed had higher scores in sexual dysfunction and lower scores in libido and sexual satisfaction than those infertile couples who were under treatment or had no infertility problems [41].

Our findings showed that the diagnosis of infertility has undesirable effects on men's sexual function and also

Table 3. Analysis of variances (ANCOVA test) from CBM, HISA and SDBQ questionnaires

\begin{tabular}{|c|c|c|c|c|c|c|}
\hline State & Dependent Variables & Sum of Squares & df & Mean of Squares & F-test & $\mathbf{P}$ \\
\hline \multirow{3}{*}{ Group } & Sexual assertiveness & 3.41 & 1 & 3.41 & 0.02 & 0.87 \\
\hline & Couple burnout & 1878.66 & 1 & 7878.66 & 10.86 & $0.01^{*}$ \\
\hline & Sexual dysfunctional beliefs & 1688.21 & 1 & 1688.21 & 4.77 & $0.03^{*}$ \\
\hline \multirow{3}{*}{ Error } & Sexual assertiveness & 17018.85 & 129 & 130.914 & & \\
\hline & Couple burnout & 21611.03 & 129 & 172.88 & & \\
\hline & Sexual dysfunctional beliefs & 45602.89 & 129 & 353.511 & & \\
\hline \multirow{3}{*}{ Total } & Sexual assertiveness & 778015 & 148 & & & \\
\hline & Couple burnout & 634423 & 130 & & & \\
\hline & Sexual dysfunctional beliefs & 2689451 & 133 & & & \\
\hline
\end{tabular}


Table 4. LSD test of mean scores of CBM, HISA, and SDBQ questionnaires

\begin{tabular}{ccccccc}
\hline Variable & $\begin{array}{c}\text { I } \\
\text { Women With } \\
\text { Infertile Husband }\end{array}$ & $\begin{array}{c}\text { Women With } \\
\text { Fertile Husband }\end{array}$ & $\begin{array}{c}\text { Mean Difference } \\
\text { (I-J) }\end{array}$ & SD & F & Sig. $^{*}$ \\
\hline Sexual assertiveness & 71.76 & 71.44 & 0.317 & 1.37 & 0.02 & 0.87 \\
Couple burnout & 72.12 & 64.52 & -0.317 & 1.39 & & 0.001 \\
\hline $\begin{array}{c}\text { Sexual dysfunctional } \\
\text { beliefs }\end{array}$ & 1.31 & 1.24 & -7.60 & 1.67 & 2.30 & 0.03 \\
\hline
\end{tabular}

*Significance from LSD test

have a greater impact on sexual arousal and sexual desire in women than in men. In general, infertility is associated with greater serious effects in women. Drosdzol and Skrzypulec stated that the diagnosis of male infertility and duration of infertility (between 3 to 6 years) contributed to increasing instability in marital relationship and less sexual satisfaction for both men and women [42]. In our study, we confirmed the effects of infertility on women's sexual disturbance and sexual behaviors. In a review study by Peng Tao et al., sexual partners of infertile couples were both affected by the infertility of the other [13]. The results of the present study also suggest the effect of husband's infertility on women's sexual dysfunction.

Contradictory results on the effect of male infertility on a couple's sexual interaction have also been obtained. Peng Tao et al., reported that male infertility did not have a negative effect on marital relationships and rather increased sexual satisfaction as expressed by infertile male participants [13]. Other authors suggested that infertility may be stressful but can provide common grounds for closer mutual support to thoughts and feelings of couples and, therefore, has a positive effect on couples' relationship and sexual behaviors [27, 43]. A lack of effect of male infertility on marital relationships has been suggested in other studies [23].

To the best of our knowledge, no study has investigated the effect of various types of infertility on sexual dysfunction in women, but the results indicate a high mean of sexual dysfunction in infertile women compared to fertile women. A limitation of this study was that it was performed in the assisted reproductive treatment centers. Given that this group of patients receives additional stresses for various reasons such as frequent trips to these centers, high costs of infertility treatments, concerns about the results of treatment and many other problems, it was hard to attract their trust. Furthermore, asking questions and answering questions about sex is difficult for most people, especially in Iranian society. In general, all these factors made sampling harder for the researcher [44-46].

\section{Conclusion}

According to the results, it seems that infertility-induced sexual dysfunction and its social and psychological consequences can cause a number of challenges in personal, social and marital life. Ultimately, this can also affect the community by affecting the pillars of the family. So, it is necessary for couples to undergo psychological rehabilitation in addition to infertility treatment programs so as to evaluate sexual dysfunction. In addition, training, consultation and treatment programs should be provided to infertile couples so that they can have a better prognosis with medical treatments despite their time consumption, high costs, and rehabilitation.

\section{Acknowledgments}

The researchers' thanks are due to all the participants and the Infertility Center of Yazd for their cooperation and support.

\section{Conflict of Interest}

The author declared no conflicts of interest.

\section{References}

[1] Jonathan S, Berek MD. Berek and novak's gynecology. Philadelphia: Lippincott Williams \& Wilkins; 2011.

[2] Graner VR, Barros SMO de. [Maternal complications and neonatal events associated with multiple pregnancies resulting from assisted reproduction techniques (Portuguese)]. Re- 
vista da Escola de Enfermagem da USP. 2009; 43(1):103-9. doi: 10.1590/s0080-62342009000100013

[3] Akhondi MM, Kamali K, Ranjbar F, Shirzad M, ShafeghatiSh, Behjati Z, et al. Prevalence of primary infertility in Iran in 2010. Iranian Journal of Public Health. 2013; 42(12):1398-404. PMCID: PMC4441936

[4] Covington SN, Hammer Burns L. Infertility counseling: A comprehensive handbook for clinicians. New York: Cambridge University Press; 2007.

[5] Evens EM. A global perspective on infertility: On under recognized public health issue. Chapel Hill: University Center North Carolina; 2004.

[6] Pines A. Couple burnout: Causes and cures. New York: Routledge; 1996.

[7] Ghavi F, Jamale S, Mosalanejad L, Mosallanezhad Z. A study of couple burnout in infertile couples. Global Journal of Health Sciences. 2016; 8(4):158. doi: 10.5539/gjhs.v8n4p158

[8] Bayar U, Basaran M, Atasoy N, Kokturk F, Arikan II, Barut A, et al. Sexual dysfunction in infertile couples: Evaluation and treatment of infertility. Journal of the Pakistan Medical Association. 2014; 64(2):138-45. PMID: 24640800

[9] Nikoubakht N, Karimi U, Bahrami H. [Couple burnout among fertilized and unfertilized women referred to valieasr reproductive center, Tehran (Persian)]. Iranian Journal of Epidemiology. 2011; 7(1):32-7.

[10] Litzinger S, Gordon KC. Exploring relationships among communication, sexual satisfaction, and marital satisfaction. Journal of Sex \& Marital Therapy. 2005; 31(5):409-24. doi: $10.1080 / 00926230591006719$

[11] Van den Akker OBA. Coping, quality of life and psychological symptoms in three groups of sub-fertile women. Patient Education and Counseling. 2005; 57(2):183-9. doi: 10.1016/j.pec.2004.05.012

[12] Cousineau TM, Domar AD. Psychological impact of infertility. Best Practice \& Research Clinical Obstetrics \& Gynaecology. 2007; 21(2):293-308. doi: 10.1016/j.bpobgyn.2006.12.003

[13] Tao P, Coates R, Maycock B. Investigating marital relationship in infertility: A systematic review of quantitative studies. Journal of Reproduction \& Infertility. 2012; 13(2): 71-80. PMID: 23926528

[14] Mills JH. [The effect of deliberate psychological education on the ego development, moral development, and sexual assertiveness of college women] [MA thesis]. Virginia: Wiliam and Mary University; 2005

[15] Nobre PJ, Pinto-Gouveia J. Dysfunctional sexual beliefs as vulnerability factors for sexual dysfunction. Journal of Sex Research. 2006; 43(1):68-75. doi: 10.1080/00224490609552300

[16] Nobre PJ, Pinto-Gouveia J. Cognitions, emotions, and sexual response: Analysis of the relationship among automatic thoughts, emotional responses, and sexual arousal. Archives of Sexual Behavior. 2008; 37(4):652-61. doi: 10.1007/s10508007-9258-0

[17] Kuffle SW, Heiman JR. Effects of depressive symptoms and experimentally adopted schemas on sexual arousal and affect in sexually healthy women. Archives of Sexual Behavior. 2006; 35(2):163-77. doi: 10.1007/s10508-005-9015-1
[18] Ghavi F, Mosalanejad L, Golestan M, Etebariy S. The investigation holistis stress in infertile women and relation to demographic characteristics in women who referred to Yazd infertility center. Biomedical and Pharmacology Journal. 2015; 8(2):1069-77. doi: $10.13005 /$ bpj/860.

[19] Inhorn MC, Patrizio P. Infertility around the globe: New thinking on gender, reproductive technologies and global movements in the $21^{\text {st }}$ century. Human Reproduction Update. 2015; 21(4):411-26. doi: 10.1093/humupd/dmv016

[20] Hargie O, Saunders C, Dickson D. Social skills in interpersonal communication. Dundee: Croom Helm; 1983.

[21] Volkman MK. Life skills: Improve the quality of your life with meta psychology. Ann Arbor: Loving Healing Press; 2005.

[22] Ménard AD, Offman A. The interrelationships between sexual self-esteem, sexual assertiveness and sexual satisfaction. The Canadian Journal of Human Sexuality. 2009; 18(12):35.

[23] Smith JF, Walsh TJ, Shindel AW, Turek PJ, Wing H, Pasch $\mathrm{L}$, et al. Sexual, marital, and social impact of a man's perceived infertility diagnosis. Journal of Sexual Medicine. 2009; 6(9):2505-15. doi: 10.1111/j.1743-6109.2009.01383.x

[24] Shifren JL, Monz BU, Russo PA, Segreti A, Johannes CB. Sexual problems and distress in United States women: Prevalence and correlates. Obstet Gynecol. 2008; 112(5):970-8. doi: 10.1097/aog.0b013e3181898cdb

[25] Santos Iglesias P, Sierra JC. Hurlbert index ofsexual assertiveness: A study of psychometric properties in a spanish sample. Psychological Reports. 2010; 107(1):39-57. doi: 10.2466/02.03.07.17.21.pr0.107.4.39-57

[26] Abdolmanafi A, Azadfallah P, Fata L, Roosta M, Peixoto MM, Nobre P. Sexual dysfunctional beliefs questionnaire (SDBQ): Translation and psychometric properties of the Iranian version. Journal of Sexual Medicine. 2015; 12(8):1820-7. doi: 10.1111/jsm.12931

[27] Schmidt L. High ratings of satisfaction with fertility treatment are common: Findings from the Copenhagen Multicentre Psychosocial Infertility (COMPI) research programme. Human Reproduction. 2003; 18(12):2638-46. doi: 10.1093/ humrep/deg505

[28] Adibrad N, Adibrad M. [Investigating relationship between relationship beliefs with marital burning and comparison of women in divorce applicants and women wanting continued life (Persian)]. Counseling Research \& Developments. 2005; 4(13):99-110.

[29] Khodabakhshi Koolaee A, Asadi E, Mansoor L, Mosalanejad L, Fathabadi A. A holistic approach to psychological sexual problems in women with diabetic husbands. Iranian Journal of Reproductive Medicine. 2014; 12(3):175-82. PMID: 24799877

[30] McCarthy BW, Bodnar LE. The equity model of sexuality: Navigating and negotiating the similarities and differences between men and women in sexual behaviour, roles and values. Sexual and Relationship Therapy. 2005; 20(2):225-35. doi: $10.1080 / 14681990500113229$

[31] Lindau ST, Schumm LP, Laumann EO, Levinson W, O'Muircheartaigh CA, Waite LJ. A study of sexuality and health among older adults in the United States. New Eng- 
land Journal of Medicine. 2007; 357(8):762-74. doi: 10.1056/ nejmoa067423

[32] Hill CA. Humansexuality: Personality and social psychological perspectives. Thousand Oaks: SAGE Publications; 2007.

[33] Billy JOG, Brewster KL, Grady WR. Contextual effects on the sexual behavior of adolescent women. Journal of Marriage and the Family. 1994; 56(2):387-404. doi: 10.2307/353107

[34] Fisher JRW, Baker GHW, Hammarberg K. Long-term health, well-being, life satisfaction, and attitudes toward parenthood in men diagnosed as infertile: Challenges to gender stereotypes and implications for practice. Fertility and Sterility. 2010; 94(2):574-80. doi: 10.1016/j.fertnstert.2009.01.165

[35] Hammarberg K, Baker HGW, Fisher J. Men's experiences of infertility and infertility treatment 5 years after diagnosis of male factor infertility: A retrospective cohort study. Human Reproduction. 2010; 25(11): 2815-20. doi: 10.1093/humrep/ deq259

[36] Wischmann TH. Sexual disorders in infertile couples. Journal of Sexual Medicine. 2010; 7(5):1868-76. doi: 10.1111/j.17436109.2010.01717.x

[37] Pawelec M, Pietras J, Watroba D, Karmowski A, Palczynski B, Karmowski M, et al. The emotional disorders of infertile couples. Advances in Clinical and Experimental Medicine. 2011; 20:641-5.

[38] Schilling K, Toth B, Rösner S, Strowitzki T, Wischmann T. Prevalence of behaviour-related fertility disorders in a clinical sample: Results of a pilot study. Archives of Gynecology and Obstetrics. 2012; 286(5):1307-14. doi: 10.1007/s00404-0122436-x

[39] Basson R. Women's sexual dysfunction: Revised and expanded definitions. Canadian Medical Association Journal. 2005; 172(10):1327-33. doi: 10.1503/cmaj.1020174

[40] Basson R. Recent advances in women's sexual function and dysfunction. Menopause. 2004; 11(Supplement):714-25. doi: 10.1097/01.gme.0000138542.65917.fb

[41] Marci R, Graziano A, Piva I, Lo Monte G, Soave I, Giugliano E, et al. Procreative sex in infertile couples: The decay of pleasure. Health and Quality of Life Outcomes. 2012; 10(1):140. doi: 10.1186/1477-7525-10-140

[42] Drosdzol A, Skrzypulec V. Evaluation of marital and sexual interactions of Polish infertile couples. The Journal of Sexual Medicine. 2009; 6(12):3335-46. doi: 10.1111/j.17436109.2009.01355.x

[43] Chachamovich J, Chachamovich E, Fleck MP, Cordova FP, Knauth D, Passos E. Congruence of quality of life among infertile men and women: Findings from a couple-based study. Human Reproduction. 2009; 24(9):2151-7. doi: 10.1093/humrep/dep177

[44] Ramezanzadeh F, Aghssa MM, Jafarabadi M, Zayeri F. Alterations of sexual desire and satisfaction in male partners of infertile couples. Fertility and Sterility. 2006; 85(1):139-43. doi: 10.1016/j.fertnstert.2005.07.1285

[45] Schmidt L, Holstein B, Christensen U, Boivin J. Does infertility cause marital benefit. Patient Education and Counseling. 2005; 59(3):244-51. doi: 10.1016/j.pec.2005.07.015
[46] Aldous J, Ganey RF. Family life and the pursuit of happiness: The influence of gender and race. Journal of Family Issues. 1999; 20(2):155-80. doi: 10.1177/019251399020002001 